\title{
Television News and Women: Impact of Television News of Flood in Kerala on Women
}

\author{
Karthika C, P.P. Vijayalakshmi
}

\begin{abstract}
Kerala, God's own Country, was taken aback with the devastating flood in August. More than 350 people lost their lives. Thousands of people remained marooned, animals were killed, houses were submerged, and vehicles were floating. The damage doesn't end there. According to the government, the State met with a loss of Rs. 20,000 crore. Malayalam Television news channels covered the flood $24 * 7$ without a break. Some of them set up helpdesks to pass information on the missing, the stranded, and the rescue efforts. Breathtaking visuals of floods were also aired. Every minute aspect of rescue operations and flood were communicated. We know that a visual speaks a thousand words. In the case of Kerala flood, some visuals created panic. Some were soothing and some were informative. This study attempts to analyze the impact of visuals aired by Malayalam television channels on women in Kuttanad. A sample of 500 respondents of age group 15-60 from different Panchayaths of Kuttanad are selected and structured questionnaires distributed to them and the response collected. The research assesses women's rationale for watching the visuals of the flood in Kerala and also its impact on Women in selected areas of Kuttanad. The objective of the research is to understand the relationship between viewers and their motives for watching television.
\end{abstract}

Keywords : Television, News, Women, Flood.

\section{INTRODUCTION}

Television is a medium that opens up multifaceted avenues of entertainment, knowledge, information and recreation. It unveils the world infront of us with more clarity and precision ((Mankekar 1993; Fernandes 2000; Johnson 2001; Scrase 2002). The impact of Television to communicate through visuals and images is incredible and remarkable. The process of communication through Television has become more and more complex and indirect. This is substantiated by the studies of Lerner (1958) who stated that the quickest way to change the mindset of the world is through the mass media like Television. Television as a mass medium is an institutionalized source of entertainment and information. Television makes the information about the outside world available to everyone and gives a wide exposure to life.

Revised Manuscript Received on July 22, 2019.

Karthika C, Assistant Professor, Dept of Visual Media \& Communication, Amrita School of Arts \& Sciences, Kochi, Amrita Vishwa Vidyapeetham, India

Dr. P.P. Vijayalakshmi, Professor Dept of English \& Languages, Amrita School of Arts \& Sciences, Kochi, Amrita Vishwa Vidyapeetham, India
This is proved in the cases of rural and remote areas where there are few sources of entertainment and recreation (Mankekar 1993; Fernandes 2000; Johnson 2001; Scrase 2002). In other words, it helps in creating novel ideas, passing new information, educating masses, enlightening people, providing recreation, creating propaganda and strengthening national integration. Television as an audio-visual medium has a greater ability and influence upon masses to convey life and events. Recent studies prove that exposure to Television news has a huge influence on the attitudes and behavior of the audience. It has the power to shape the outlooks, perceptions and even channelize their beliefs.

Television News Transmission of any kind of information or disseminating current events through the medium of television is termed as Television News. News Bulletin is defined as a programme that has a duration ranging from few seconds to hours and which provides knowledge about the happenings around the globe. TV news is said to be image-based or in other words visuals tells the story in a TV news.

Today, Television news is a part of the social process. It has greater impact on social policy making than in any other mass media. Accessibility, visual quality, drama and action, audience familiarity with prior messages, and thematic encapsulation make News more and more impactful. (Altheide, 1991).

\section{Flood in Kerala}

Kerala, God's own country, was taken aback with the devastating flood in August. More than 350 people lost their lives. Thousands of people remained marooned, animals were killed, houses were submerged, and vehicles were floating. The damage doesn't end there. According to the government, the State met with a loss of Rs. 20,000 crore. One-sixth of the total population have been directly affected by the disaster and related incidents.

There were a lot of criticisms regarding the telecasting. Veteran Journalist K. Kunjikkannan lashed out against the kind of sensationalism practiced by the Television News Channels (Kunjikkannan, 2018). He also appreciated the step taken by some private channels to stop airing advertising and giving more priorities to flood related news.

According to Parthasarathi Committee report (1982), during natural calamities Media ought to give importance, time and space for such information. General public will be eager to know about such 
news. Hence, it is not fair to give hype to death toll or other related items. It is the responsibility of the media to depend solely on official sources so as not to create panic in the people. These are clearly stated in the guidelines provided by Central Information and Broadcasting Ministry.

The news must be accurate and specific. It must give warning to people regarding the intensity of the calamity and so that the depth of the disaster can be reduced. It must be helpful for the rescue operations.

The importance of TV news is underlined and understood during the time of flood. Malayalam Television news channels covered the flood $24 * 7$ without a break. Some of them set up helpdesks to pass information on the missing, the stranded, and the rescue efforts. Breathtaking visuals of floods were also aired. Every minute aspect of rescue operations and flood were communicated. We know that a visual speaks a thousand words. In the case of Kerala flood, some visuals created panic. Some were soothing and some were informative. It is obvious that the television news channels extended a humane touch to the news they covered during the time of flood.

\section{Flood-hit Kuttanad}

Kuttanad, rice-bowl of Kerala is one of the most flood affected areas. Flood water has ravaged a vast region. Several thousands lost their lives and livelihood. According to the government sources 86,839 people from about 20000 families had been relocated to relief homes (Worst floods in last two decades ravage Kuttanad. 2018). As the water level rose, several hectares of the paddy fields had been sub-merged. According to Kerala Agricultural Department officials, flood has destroyed 7000 hectare of paddy (Worst floods in last two decades ravage Kuttanad. 2018).

\section{LITERATURE REVIEW}

A survey on different studies related to impact of mass media, especially television has been done. There are many studies that establishes social, economic, political, health and psychological impacts of television on viewers. But little effort has been made to analyse the impact of television news on women. Some of the literatures that have been reviewed are mentioned below:

Television is an agent of socialization. The visual images telecast through television help in shaping attitudes of masses (Lay, Gorman \& David, 2009). The availability of cable Television and satellite give more options of channels to the women in urban areas and thereby have an influence in shaping their attitude and behaviour (Sheikh, 2007). Content analysis of recent Television programmes have found that there has been a changing trend in the portrayal of women in Television programs.

The creators of the programmes depict women in positive spirited roles unlike the earlier stereotyped roles or showing women only in domestic life (Ross, K., \& Byerly, C. M. (2006). Holbert, Shah, \& Kwak (2003) have also identified this positive change in the portrayal of women in Television programmes. Recent programmes in a way act as an agent for the upliftment of social status of women and also provide stuff for women rights and issues. This helps in developing more liberal thoughts and weakening conservative attitudes of the society.

In the study "Television and Social Change in Rural India", it is found that the people in rural areas of the country have been highly influenced by the Television viewing. This habit has even brought changes in their psychological and structural patterns. Political awareness, economic decisions, personal relationships and total outlook about the world have been transformed. The power of television is that it has taken the position of the traditional dispute solvers as it improves and increases their awareness of rights (Johnsons, 2000).

A study on Cable TV and Status on women in Rural India found that the widespread of Cable Television improved the status of women in several ways. The domestic abuses are not at all considered as natural and conventional; they started to respond and react. Conservative preference for boy child than girls has also been changed. It was found that women got more autonomy in households, daily chores and in decision making processes of the family. Also fertility rate has also come down. The researcher argues that cable TV is also associated with increase in school enrollment of girls (Jenson\&Oster, 2004).

The study Television on Women Empowerment in India (Ting, Ato \& Lin, 2014) found that television is a mass media that makes women aware about their right, power and autonomy. Women who watch television regularly are more financially independent, more health conscious, know how to avoid unwanted pregnancies and are strong decision makers.

In another study by Tunio \& Shaukath (2015) found that television has a positive impact on its women viewers. Television viewing increases their awareness about their socio-economic rights. It acts as a medium to educate women about laws against domestic and other violence. Also, it informs new conventions and developments made at national and international level to protect and promote women rights. In a study on how mass media spread health awareness, it is found that women with different age group refer all kinds of media including newspapers and health magazines to get health related information (Meti, 2014)

However, these positive stories are not that wide and universal. Television transmissions images are still less pro women. The stereotypical portrayal of women on screen is that of the mostly dependent, irrational, domestic, inferior and subordinate to men (Akhileshwari, 1984). In the study "Media Utilization for the Development of Women and Children, the researcher urges for the need for creating Television contents to educate women, give them awareness of health, nutrition, their rights, and importance of education (Akhileshwari, 1984). Television has become a part and parcel of life irrespective of age, gender, income or education. A study on TV and Children (Kanth, 2012), inferred that any kind of information passed through TV can deeply influence children and

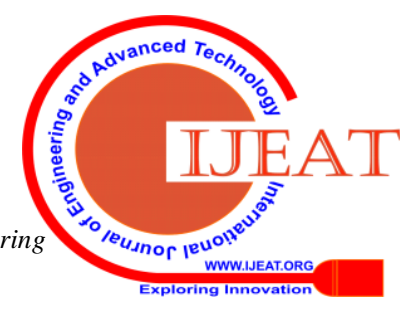


they may tend to imitate it.

In a recent study "Reach of Television: Viewing Habits and Patterns in Kerala", it is found that women prefers entertainment programmes like Serials and movies to information programmes. The researcher used questionnaire survey for the analysis (Karthika, Vijayalakshmi \&Pai, 2018).

\section{SIGNIFICANCE OF THE STUDY}

Media analysis is an integral part of the society to gauge its positive and negative impact on the audience.

In the case of television, TV viewing is so closely attached with the audience as it depicts the society as such. And hence, its effect and impact is also huge. There are a plenty of government run and private agencies to measure the reach of Television programmes. Several researches are being taken out to measure the psychological, social and cultural impact of these programmes also.

When considering the impact of TV news on women, several factors including their social, cultural, and marital and physical health especially psychological aspects have to be measured. TV news is a tool for communicating new and novel information that may have an impact on day-to-day life directly or indirectly. The rapid change in living standards and life styles have altered the outlook of society. Their need and demand for news have changed. Not only that, the reason for the need for news has also changed. Technology has developed. Now, the news is available in their pockets. Earlier they have to wait for the very next day (or even days) to get informed about the world around them through newspapers. This place has been taken out by TV news in the first decade of this century with the arrival of $24 * 7$ news channels. Gradually, internet and news media take over this position.

However, this study proves that the power of news channels to impact and affect their audience is enhanced during the time of flood. Apart being a mass medium, its dimensions were versatile during this period.

\section{METHODOLOGY}

To research is to get nearer to truth, to understand reality (Karthika, Vijayalakshmi \&Pai, 2018). Questionnaire Survey is the methodology used in this study since the research aims to find out the "Television News And Women : Impact Of Television News Of Flood In Kerala On Women". A structured questionnaire is given to the 500 women from different areas of Kuttanad and is asked to fill it out. Purposive sampling is opted to collect the relevant data.

\section{THEORETICAL FRAMEWORK}

According to Gerbner, Television shapes or cultivates viewers' perception of society. When exposed to television over a period of time, the perception of social reality for individuals will gradually be altered (Mass Media
,2012).This will ultimately affect our outlook towards the whole world. Gerbner argues that "the mass media cultivate attitudes and values which are already present in a culture: the media maintain and propagate these values amongst members of a culture, thus binding it together" (Gerbner and Gross, 1976).

In this study, it is found that over exposure to television news during the flood time has cultivated certain perception like fear, grief, empathy, sympathy and relief.

\section{RESEARCH DESIGN}

Five hundred samples from different areas of Kuttanad have been selected. A structured questionnaire of 20 questions was distributed among them and were asked to fill. Here a quantitative analysis is used. Based on this information, a qualitative interpretation of their responses were done. This is also done to analyze the impact of Malayalam television news channels on women in Kuttanad.

\section{OBJECTIVES}

- To identify the reach of Malayalam television news on women in Kuttanad during the flood

- To identify the impact of Malayalam television news channels on women in Kuttanad.

\section{LIMITATIONS OF THE STUDY}

- The geographical area of the study is limited to Upper and Lower Kuttanad of Alappuzha District in Kerala.

- Women of age group above 15 to 80 have been considered for data collection according to concept of the study.

\section{FINDINGS AND ANALYSIS}

Table No.1 Demographic Table

\begin{tabular}{|l|l|l|l|l|}
\hline $\begin{array}{l}\text { Age } \\
\text { group }\end{array}$ & $15-30$ & $31-45$ & $46-60$ & 61 \& above \\
\hline & 15 & 205 & 215 & 65 \\
\hline $\begin{array}{l}\text { Educati } \\
\text { on }\end{array}$ & $\begin{array}{l}\text { Upto } \\
\text { Plus Two }\end{array}$ & Degree & PG & Others \\
\hline & 210 & 195 & 85 & 10 \\
\hline Income & $0-15,000$ & $\begin{array}{l}15,001 \\
-30000\end{array}$ & $\begin{array}{l}30,001- \\
45000\end{array}$ & $\begin{array}{l}45,001 \\
\text { \&above }\end{array}$ \\
\hline & 340 & 120 & 30 & 10 \\
\hline
\end{tabular}

Table 1 shows the demographic details of the respondents participated in the survey conducted among women in Kuttanad. There were 15 respondents of age group 15-30, 205 respondents in the age group 31-45, 215 respondents are from the age group 46- 60 and 65 respondents are from the age group 61 and above. Among these, 210 respondents are educated up to Plus Two, 195 have Degree, 85 are PG holders and 10 marked other qualification like Diploma. 340 respondents have marked their income as between 015,000 Rs per month, 120

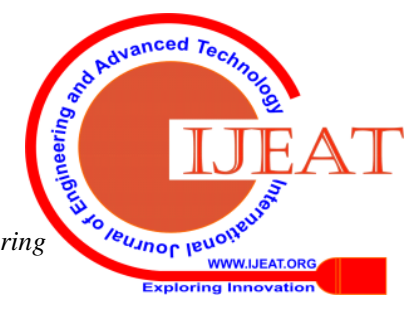


respondents have $15001-30,000,30$ women have $30,001-45,000$ and 10 respondents have an income more than 45,001 per month.

\section{REACH OF MALAYALAM TELEVISION NEWS ON WOMEN IN KUTTANAD}

News is something new, novel, informative and educative. It is a cliché thought that women are least bothered about news and information. Some movies present women reading newspapers to know the gold rate and obits. But is this the real situation? Aren't they interested in news and everyday happenings around the world? Aren't they interested in current affairs? Why do they watch TV?

The survey shows 480 respondents among the total 500 find time to watch at least a news bulletin every day. Interestingly, 495 respondents watched TV news keenly during the flood time.

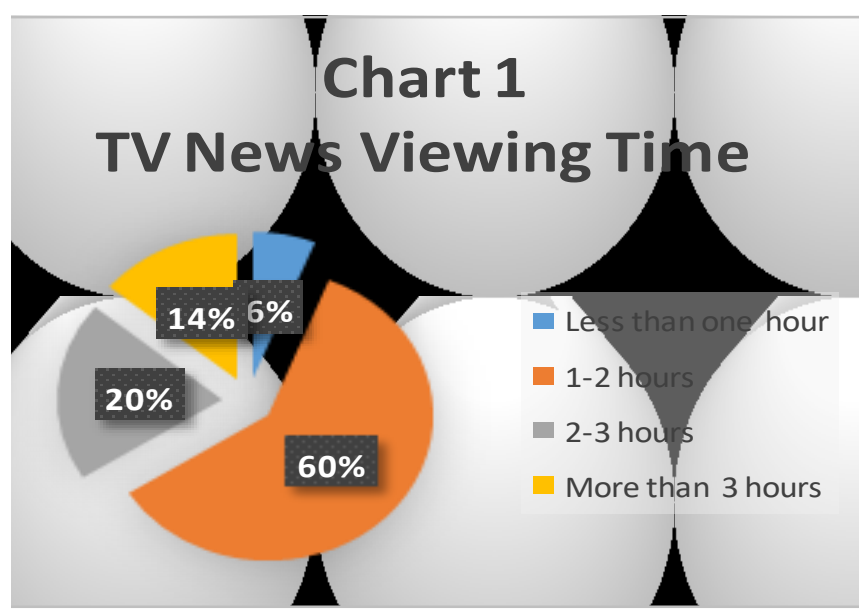

Chart 1 shows how much time was spent for viewing TV News during the flood by the respondents participated in the survey. $6 \%$ of the total respondents spent less than an hour to watch TV News during the flood. $60 \%$ of the total respondents spent 1-2 hours a day to watch TV news during the flood time. $20 \%$ of the respondents spent 2-3 hours a day and $14 \%$ spent more than three hours a day to watch TV News.

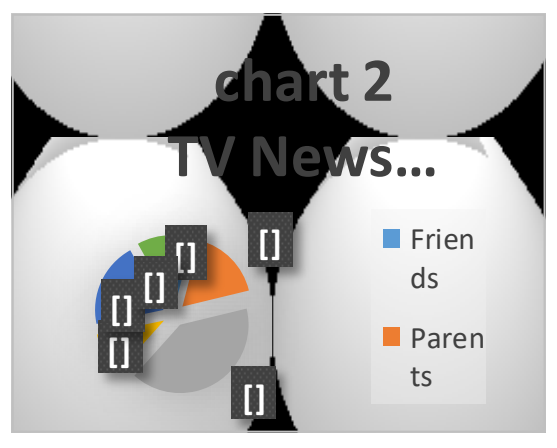

Chart 2 depicts the TV news viewing habits of the women. 41 per cent of the respondents claimed that they view TV News with their husbands. 20 per cent watched with siblings, 17 per cent with parents, 10 per cent with relatives, 8 per cent with neighbours and 4 per cent of those participated in the survey said that they viewed TV news with friends. From the above two data, we can understand the reach of TV news during the flood. Women, showed keen interest in watching news. They spent hours in front of the TV to watch news. The quest for new updates regarding flood held them on. Interestingly, 94 per cent of the women who took part in the survey were forced to leave their home. They found shelters in relief camps organized by government and in the homes of their relatives. Even then, TV news was something they could not avoid.

The study Gender and Journalism (Stenier, 2018) argues that gender is something that is constructed socially and it is not at all biological. In the case of journalism too, this socially constructed 'genderedness' can be seen. Feminist activist and founding editor of Ms. magazine, Gloria Steinem said: "It's hard to think of anything except air, food, and water, that is more important than the media ... It creates for us the idea of normal, whether or not the normal is accurate ... If we can't see it, we can't be it" (Zernike, 2014, p. A20). So is the case here or more important. News is just like air, food and water. It was a part of their lives at that particular time. To stay alive was the biggest challenge for them. Hence, they had to depend all available sources of information. TV news channels stood as a saviour for them at that time. They opened help desks, disbursed all kinds of new information filtered in a better way. Their commendable job helped many.

\section{Impact Of Malayalam Tv News Channels ON WOMEN}

The reason for viewing TV varies from person to person. So is the case of gratifications they receive. Here we listed out 8 gratifications and asked them to mark the one which received or sought for most during the flood while watching TV news. The responses are figured in the chart below:

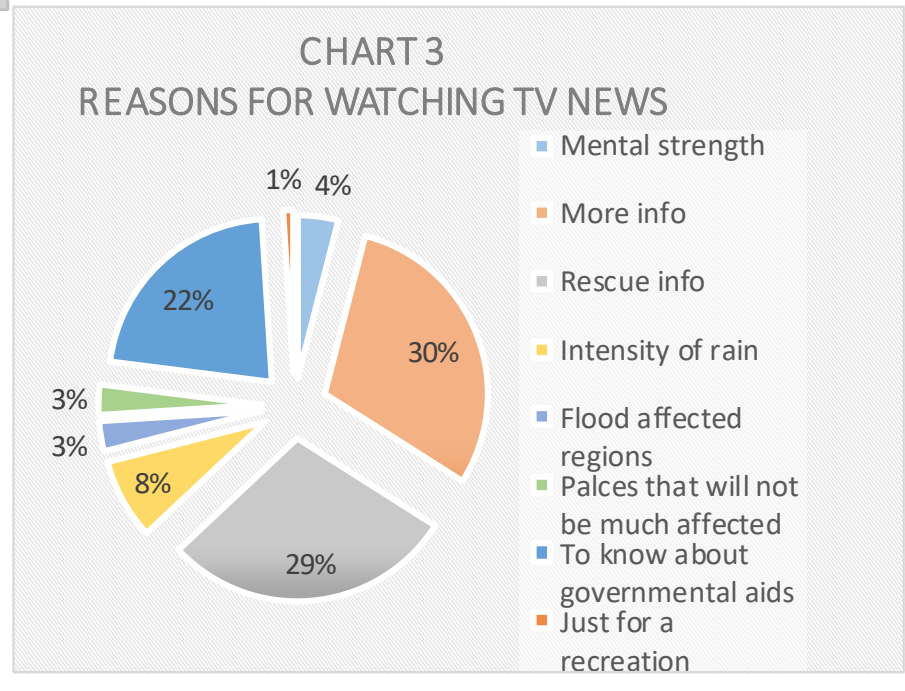

In the survey, respondents admitted that they watch television news for various reasons. 30 percent of the total respondents watched news for gaining new information regarding the flood and rain. 29 per cent of the respondents said, the news was helpful to gain information related to rescue operation. For another 8 per cent, news was helpful to get informed about the intensity of the rain. 3 per cent watched news to know about the flood affected areas and another three per cent watched news to know about the probable places that will not be flood-hit.

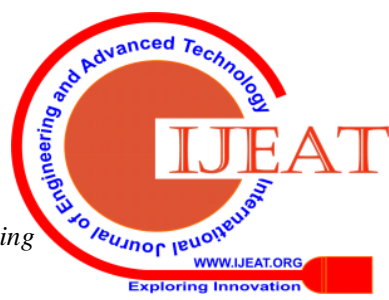


22 per cent of the respondents said they watched news to know about governmental aids, that may be immediate or in the nearby future. Interestingly, only one percent of the total respondents admitted that they watched TV news during the flood for just a recreation. 33 percent of the respondents who participated in the survey were of the opinion that the TV news channels sensationalized the whole calamity.

\section{Chart 4 TV NEWS VIEWING Vs EMOTIONS}

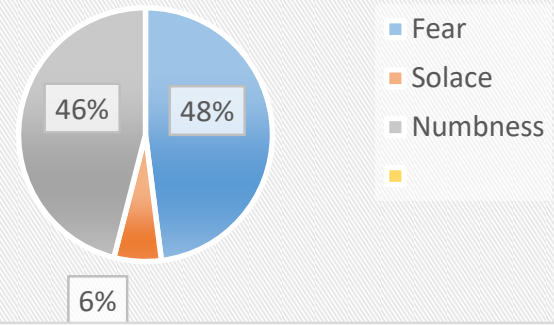

Chart 4 shows the Emotions created in relation to TV news viewing during the flood in Kerala among women. 48 per cent of the total respondents said that they felt frightened by seeing the dreadful visuals of rain, flood, soil erosion, dead bodies etc. For another 46 per cent, watching Television news gave solace and relief as it gave accurate update regarding rescue operations. The rest 6 per cent said they felt shocked and numb after seeing all those visuals and news. Most of them opined that the visuals of soil erosion, destruction of houses and buildings, downpour, heavy water flow, crying children, faces of people in relief camps, worries of those who were trapped were all terrifying and alarming. Television being a popular medium has an instant yet wide appeal. Although it has a mass heterogeneous range of audience, its impact is appreciative but gullible (Usha, 2004). Hence, the socio-political consequence of the messages passed through this medium is immediate and vast. The researcher is of the opinion that there is hardly any question of using the intelligence or discerning faculty by the viewers. However, in this study, it is clearly found that women have strong reasons for watching Television news. Mostly, it was their own decision to switch to TV news channels during the flood. They used both their emotions and intelligence for this choice.

\section{CONCLUSION}

In 2009, UNSCO released a report stating that the common images of women in the media are "the glamorous sex kitten, 3 the sainted mother, the devious witch, the hard-faced corporate and political climber" (UNESCO, 2009). The report also argued that it would take much time to achieve gender equality in media. Every step to avoid stereotypes is persuasively fitting them again to cliché. Here comes question of impact of Television news on Women audience. The current study finds that among the total respondents who participated in the survey, $60 \%$ spent 1-2 hours a day to watch TV news during the flood in Kerala. This is a clear depiction that women show keen interest in watching news. The reason for watching news may vary. 30 percent of the total respondents watched news for gaining new information regarding the flood and rain whereas 29 per cent said it was helpful to gain information related to rescue operation. For the 48 per cent the visuals of rain, flood, soil erosion, dead bodies etc. were terrifying. This is a clear inference on how TV news has a huge impact on women in Kuttanad during the flood time. They depended on TV news for various reasons and it provided them a wide range of gratification including relief, security feeling, and so on.

\section{REFERENCES}

1. Altheide, D. L. (1991). The impact of television news formats on social policy. Journal of Broadcasting \& Electronic Media,35(1), 3-21. doi:10.1080/08838159109364099.

2. Fernandes, L(2000), "Nationalizing 'The Global': Media images, Cultural Politics and the Middle Class in India," Media, Culture and Society, 22, 611-628.

3. Gerbner, G., \& Gross, L. (1976). The scary world of TV's heavy viewer. Psychology Today, 10(4), 41-89

4. Holbert, R. (2003). "Environmental Concern, Patterns of Television Viewing, and Pro-Environmental Behaviors: Integrating Models of Me". https://doi.org/10.1207/s15506878jobem4702

5. Jensen, R \&Oster, E (2009). The Power of TV: Cable Television and Women's Status in India, The Quarterly Journal of Economics, Volume 124, Issue 3, 1 August 2009, Pages 1057-1094, https://doi.org/10.1162/qjec.2009.124.3.1057

6. Johnsons, Kirk (2000) "Television and Social Change in Rural India" Sage Publication,India

7. Johnson, K (2001), "Media and Social Change: the Modernizing Influences of Television in Rural India," Media, Culture and Society, 23, 147-169.

8. Karthika, C., Vijayalakshmi, P. P., Pai, M. L., (2018). The Reach of Television: Viewing Habits and Patterns in Kerala, 118(18), 1319-1332.

9. Lerner, D (1958). The Passing of Traditional Society: Modernizing the Middle East. Second Printing. Glencoe, Ill.: Free Press.

10. Lyn, Gorman and David Mclean (2009) "Media and Society" into the 21 st century, A historical Introduction, Wiley Blackwell publication, Singapore

11. Meti, V. (2014). Mass Communication \& Journalism Impact of Television Health Programmes on Women: A Study on Gulbarga Television Viewers, 4(4), 4-7. https://doi.org/10.4172/2165-7912.1000187

12. Mankekar, P(1993), "National Texts and Gendered Lives: An Ethnography of Televsion Viewers in a North Indian City," American Ethnologist, 20 , 543-563.

13. Kunjikkannan (2018), "Pralayakalathe Television Varthakal", Media

14. R. Akhileshwari (1984)."Media utilization for the development of women and children"

15. Paper published in proceeding of Indian council for communication training and research with UNICEF

16. Ravi, Kanth. "Television and Creativity." Online International Interdisciplinary Research Journal, vol. 2, May 2012.

17. Ross, K., \& Byerly, C. M. (2006). Women and Media: A Critical Introduction. USA, UK,Australia: Blackwell Publishing Ltd.

18. Scrase, T (2002), "Television, the middle classes and the transformation of cultural identities in West Bengal, India," Gazette: The International Journal for Television Studies, 64, 323-342.

19. Sheikh, M. A. (2007). "Satellite television and social change in Pakistan: A case study of rural Sindh". Karachi: Orient Books Publishing House.Steiner, L. (2018). Oxford Research Encyclopedia of Communication Gender and Journalism, (December), 1-25. https://doi.org/10.1093/acrefore/9780190228613.013.91

20. Ting, H., Ao, C., \& Lin, M. (2015). Television on Women 's Empowerment in India The Journal of Development Studies Television on Women' $\mathrm{s}$ Empowerment in India, (June 2014). https://doi.org/10.1080/00220388.2 014.896456.

21. Tunio, S., \& Shouakt, G (September, 2015). Role of 
Television in Awareness of Women Rights among Women Folk with Special Focus on Women of District Naushahro Feroze.

22. Usha, V. T. (2004.). Gender, Value, and Signification: Women and television in Kerala.

23. Zernike, K. (2014). Rutgers is to name a chair for Steinem, New York Times, Sept. 27, p. A20.

24. Mass Media | Cultivation Theory. (2012). Retrieved from https://www.utwente.nl/en/bms/communication-theories/sorted-by-clu ster/Mass-Media/Cultivation_Theory/

25. Worst floods in last two decades ravage Kuttanad. (2018, July 18). Retrieved from https://www.thehindu.com/news/national/kerala/worst-floods-in-last-t wo-decades-ravage-kuttanad/article24454838.ece

26. https://www.unicef.ie/wp-content/themes/iboot-child/micro-sites/itsab outus/cards/unicef-itsaboutus-gender-media.pdf

27. http://www.indiawaterportal.org/articles/parthasarathy-committee-rep ort-technical-committee-watershed-programmes-india-2006 